\title{
IMPLEMENTASI SISTEM PENJAMINAN MUTU INTERNAL SEBAGAI UPAYA MENINGKATKAN MUTU PENDIDIKAN DI UNIVERSITAS GADJAH MADA
}

\author{
Ahmad Sulaiman, Udik Budi Wibowo \\ Universitas Gadjah Mada, Universitas Negeri Yogyakarta \\ ahmad.ugm@gmail.com, yube2u@yahoo.com
}

\begin{abstract}
Abstrak
Penelitian ini bertujuan untuk menggambarkan implementasi Sistem Penjaminan Mutu Internal (SPMI) sebagai upaya meningkatkan mutu pendidikan di Universitas Gadjah Mada. Studi ini merupakan penelitian kualitatif dengan metode studi kasus. Penelitian dilakukan di Universitas Gadjah Mada, dengan subjek Kantor Jaminan Mutu (KJM UGM). Teknik pengumpulan data: observasi langsung, penelusuran dokumen dan arsip, serta wawancara. Hasil penelitian menunjukkan: (1) Kebijakan dan konsep SPMI berupa dokumen akademik dan dokumen mutu disusun oleh KJM UGM; (2) KJM UGM sebagai koordinator dalam merencanakan dan melaksanakan SPMI di seluruh universitas; (3) Implementasi SPMI dilaksanakan dengan penyusunan rancangan berupa Siklus SPMI; (4) Kendala yang dihadapi: komitmen pimpinan, jumlah tenaga auditor, kegiatan SPMI menjadi rutinitas; (5) Langkah yang ditempuh: menyediakan tenaga expert penjaminan mutu, pelatihan auditor, membangun semangat penjaminan mutu; (6) Evaluasi Implementasi SPMI dilaksanakan setiap tahun; (7) Pemanfaatan hasil implementasi SPMI: membangun budaya mutu, akreditasi dan sertifikasi nasional dan internasional; dan (8) Pengembangan implementasi SPMI mengacu pada manajemen mutu ISO dan standar BAN PT.
\end{abstract}

Kata kunci: implementasi SPMI, penjaminan mutu, mutu pendidikan

\section{THE IMPLEMENTATION OF INTERNAL QUALITY ASSURANCE SYSTEM AS AN EFFORT TO IMPROVE QUALITY OF EDUCATION AT GADJAH MADA UNIVERSITY}

\author{
Ahmad Sulaiman, Udik Budi Wibowo \\ Universitas Gadjah Mada, Universitas Negeri Yogyakarta \\ ahmad.ugm@gmail.com, yube2u@yahoo.com
}

\begin{abstract}
This study aims to describe the implementation of the Internal Quality Assurance System (IQAS) as an effort to improve quality of education at Gadjah Mada University. This study is a qualitative research with case study method. Research conducted at Gadjah Mada University, the subject of research is the Quality Assurance Office (KJM UGM). Data collection techniques: direct observation, review of archive documents, and interviews. The results showed as follows: (1) Policies and concepts of IQAS consist of academic documents and quality documents compiled by KJM UGM; (2) Organizing IQAS conducted by KJM UGM in planning and implementing of IQAS; (3) Implementation of IQAS conducted by drafting the plan of IQAS Cycle; (4) Constraints faced: leadership commitment, the number of auditors, IQAS activity become routine; (5) Steps taken to overcome the constraints: providing expert quality assurance personnel, auditor training, building a passion for quality assurance; (6) Evaluation of the Implementation of IQAS held every year; (7) Utilization of the results of the implementation of IQAS: building the culture of quality, accreditation and certification both national and international; and (8) Development of implementation of IQAS refered to the quality management of ISO and the standard of BAN PT.

Keywords: implementation of IQAS, quality assurance, quality of education
\end{abstract}




\section{Pendahuluan}

Pendidikan merupakan kebutuhan mendasar manusia yang sangat penting. Pendidikan adalah usaha sadar dan terencana untuk mewujudkan suasana belajar dan proses pembelajaran agar peserta didik secara aktif mengembangkan potensi dirinya untuk memiliki kekuatan spiritual keagamaan, pengendalian diri, kepribadian, kecerdasan, akhlak mulia, serta keterampilan yang diperlukan dirinya, masyarakat, bangsa dan negara. Permasalahan pendidikan yang sangat dirasakan sekarang ini adalah rendahnya mutu pendidikan di berbagai jenis dan jenjang pendidikan. Rendahnya mutu pendidikan akan menghambat penyediaan sumber daya manusia yang mempunyai pengetahuan, keahlian dan keterampilan untuk memenuhi sumber daya manusia pembangunan bangsa Indonesia.

Sebagai upaya meningkatkan mutu pendidikan, pemerintah melalui Kementerian Pendidikan dan Kebudayaan mengeluarkan kebijakan tentang penjaminan mutu pendidikan. Upaya penjaminan mutu pendidikan oleh pemerintah kemudian diimplementasikan ke dalam Sistem Penjamian Mutu Pendidikan (SPMP). Sesuai dengan Peraturan Menteri Pendidikan Nasional Nomor 63 Tahun 2009 pasal 1 ayat (3) yang menyebutkan bahwa "Sistem Penjaminan Mutu Pendidikan yang selanjutnya disebut SPMP adalah subsistem dari Sistem Pendidikan Nasional yang fungsi utamanya meningkatkan mutu pendidikan". Tujuan akhir penjaminan mutu pendidikan adalah tingginya kecerdasan kehidupan manusia dan bangsa sebagaimana dicitacitakan oleh Pembukaan Undang-undang Dasar Negara Republik Indonesia Tahun 1945 yang dicapai melalui penerapan Sistem Penjaminan Mutu Pendidikan.

Pendidikan tinggi merupakan bagian dari sistem pendidikan nasional memiliki peran strategis dalam mencerdaskan kehidupan bangsa dan memajukan ilmu pengetahuan dan teknologi. Peran strategis pendidikan tinggi ini tetap memperhatikan dan menerapkan nilai humaniora serta pemberdayaan bangsa Indonesia yang berkelanjutan. Pendidikan tinggi juga berperan dalam meningkatkan daya saing bangsa dalam menghadapi globalisasi di segala bidang. Oleh karena itu diperlukan pendidikan tinggi yang mampu mengembangkan ilmu pengetahuan dan teknologi serta menghasilkan intelektual, ilmuwan, dan/atau profesional yang berbudaya dan kreatif, toleran, demokratis, berkarakter tangguh, serta berani membela kebenaran untuk kepentingan bangsa.

Penjaminan mutu perguruan tinggi adalah proses perencanaan, pemenuhan, pengendalian, dan pengembangan standar pendidikan tinggi secara konsisten dan berkelanjutan, sehingga pemangku kepentingan (stakeholders) internal dan eksternal perguruan tinggi, yaitu mahasiswa, dosen, karyawan, masyarakat, dunia usaha, asosiasi profesi, pemerintah dapat memperoleh kepuasan atas kinerja dan keluaran perguruan tinggi. Kegiatan penjaminan mutu ini merupakan perwujudan akuntabilitas dan transparansi pengelolaan perguruan tinggi. Sesuai Undang-undang Nomor 12 tahun 2012 tentang Pendidikan Tinggi, Sistem Penjaminan Mutu Pendidikan Tinggi (SPMPT) terdiri atas Sistem Penjaminan Mutu Internal (SPMI) dan Sistem Penjaminan Mutu Eksternal (SPME). SPMI dikembangkan oleh Perguruan Tinggi yang bersangkutan, sedangkan SPME dilakukan melalui akreditasi.

Sistem Penjaminan Mutu Internal (SPMI) di suatu perguruan tinggi merupakan kegiatan mandiri dari perguruan tinggi yang bersangkutan sehingga proses tersebut dirancang, dijalankan, dan dikendalikan sendiri oleh perguruan tinggi yang bersangkutan tanpa campur tangan dari pemerintah. Pemerintah membuat pedoman dalam pelaksanaan SMPI yang bertujuan untuk memberikan inspirasi tentang berbagai aspek yang pada umumnya terkandung dalam SPMI di suatu perguruan tinggi. Hal ini dilakukan karena setiap perguruan tinggi memiliki spesifikasi yang berlainan, dalam hal sejarah, visi dan misi, budaya organisasi, ukuran organisasi, struktur, sumber daya, dan pola kepemimpinan. Agar perguruan tinggi senantiasa 
mampu memenuhi tuntutan kebutuhan stakehoders yang terus berkembang, maka SPMI juga harus selalu disesuaikan dengan perkembangan tersebut secara berkelanjutan (continuous improvement).

Universitas Gadjah Mada merintis dan mengembangkan konsep sistem penjaminan mutu internal (SPMI) perguruan tinggi. Konsep tersebut meliputi definisi penjaminan mutu, siklus implementasi penjaminan mutu, organisasi, sistem dokumentasi, dan sumber daya manusia. SPMI di UGM dilakukan oleh Kantor Jaminan Mutu (KJM UGM) yang bertugas merencanakan dan melaksanaan sistem jaminan mutu secara keseluruhan di UGM.

Implementasi sistem penjaminan mutu pendidikan di perguruan tinggi sesuai dengan Pedoman Penjaminan Mutu (Quality Assurance) Pendidikan Tinggi (2003, pp.16-19) dapat dilaksanakan, bila dipenuhi beberapa prasyarat, yaitu: komitmen, perubahan paradigma, dan sikap mental para pelaku proses pendidikan tinggi, serta pengorganisasian penjaminan mutu di perguruan tinggi. Implementasi sistem penjaminan mutu di perguruan tinggi sering menemui kendala/hambatan di lapangan antara lain; kesadaran para pelaku proses pendidikan tentang arti penting penjaminan mutu sebagai kebutuhan stakeholders masih rendah, komitmen para pelaku proses pendidikan tinggi untuk menjamin dan meningkatkan mutu pendidikan masih kurang, pemahaman terhadap konsep dan implementasi SPMPT oleh sivitas akademika belum merata, tata kelola dan mekanisme kerja penjaminan mutu belum terbangun dengan utuh, pemberdayaan sumber daya manusia khususnya para dosen untuk mendukung sistem penjaminan mutu belum optimal, dan pemanfaatan teknologi informasi dan komunikasi untuk mendukung sistem penjaminan mutu internal belum optimal.

Universitas Gadjah Mada merupakan universitas terbaik di Indonesia dan satusatunya universitas di Indonesia yang masuk 100 universitas terbaik di Asia. Konsep dan Implementasi Sistem Penjaminan Mutu Perguruan Tinggi di UGM telah dibuat dan disosialisasikan kepada seluruh pimpinan, pengurus, dosen, mahasiswa, dan tenaga kependidikan di tingkat universitas dan fakultas. Keberhasilan implementasi SPMI di UGM tidak lepas dari peran serta seluruh sivitas akademika dalam mendukung kegiatan penjaminan mutu internal untuk kepuasan stakeholders. Meskipun demikian, beberapa kendala masih ditemui dalam implementasi SPMI di UGM. Kendala utama yang dirasakan adalah komitmen pimpinan baik di tingkat universitas, fakultas, jurusan, maupun program studi, terkait posisi dan kesibukannya sebagai SDM penjaminan mutu sekaligus sebagai dosen relatif masih kurang. KJM UGM merasakan masih kurangnya SDM auditor, sehingga setiap tahun memprogramkan pelatihan auditor baru untuk mencapai jumlah auditor yang ideal. Kegiatan SPMI yang menjadi rutinitas ini menyebabkan tidak terjadinya improvement yang mengakibatkan kebosanan.

Implementasi SPMI di perguruan tinggi sering menemui masalah, antara lain: (1) kesadaran para pelaku proses pendidikan terhadap arti penting penjaminan mutu sebagai kebutuhan stakeholders relatif masih rendah; (2) pemahaman konsep sistem penjaminan mutu pendidikan oleh sivitas akademika untuk meningkatkan mutu pendidikan masih belum merata; (3) komitmen para pelaku proses pendidikan tinggi di perguruan tinggi, baik yang memimpin maupun yang dipimpin untuk senantiasa menjamin dan meningkatkan mutu pendidikan relatif masih kurang; (4) Ketersediaan sumber daya manusia khususnya tenaga auditor untuk mendukung SPMI masih belum terpenuhi; dan (5) implementasi SPMI sering menjadi sebuah rutinitas menyebabkan sulit untuk mengukur ketercapaian perbaikan berkelanjutan.

Penelitian ini bertujuan untuk mengetahui implementasi sistem penjaminan mutu internal dalam upaya meningkatkan mutu pendidikan di Universitas Gadjah Mada. Secara spesifik, penelitian ini bertujuan untuk: mendeskripsikan proses perencanaan, implementasi, serta kendala yang dihadapi dalam pelaksanaan sistem 
penjaminan mutu internal secara keseluruhan di Universitas Gadjah Mada, proses evaluasi serta pemanfaatan hasil implementasi sistem penjaminan mutu internal dalam rangka meningkatakan mutu pendidikan secara berkelanjutan di Universitas Gadjah Mada. Hasil penelitian ini diharapkan mampu memperkaya khasanah ilmu dan pengetahuan tentang implementasi SPMI untuk peningkatan mutu pendidikan tinggi di Indonesia.

Mutu mengandung makna derajat (tingkat) keungggulan suatu produk (hasil kerja) baik berupa barang maupun jasa. Pengertian mutu secara garis besar adalah gambaran dan karakteristik menyeluruh dari produk atau jasa yang menunjukkan kemampuannya dalam memenuhi kebutuhan, harapan, dan kepuasan pelanggan.

Oakland (1993, p.5) menyatakan bahwa "Quality is used to signify 'excelence' of a product or service". Mutu digunakan untuk menunjukkan 'keunggulan' dari sebuah produk atau jasa. Suatu produk atau jasa dikatakan bermutu apabila mempunyai keunggulan dibanding produk atau jasa yang lain. Macdonald (1993, p.6) dalam menyatakan "A useful definition is, 'quality means conformance to requirements'. That allows us to measure quality. We know when we do or do not conform to requirements". Mutu berarti kesesuaian dengan persyaratan. Persyaratan yang memungkinkan untuk mengukur kualitas dengan mengetahui bahwa sesuatu itu memenuhi syarat tertentu untuk dikatakan berkualitas. Tjiptono \& Diana $(1995$, p.2) menyatakan: "Konsep kualitas itu sendiri sering dianggap sebagai ukuran relatif kebaikan suatu produk atau jasa yang terdiri atas kualitas desain dan kualitas kesesuaian. Kualitas desain merupakan fungsi spesifikasi produk, sedangkan kualitas kesesuaian adalah suatu ukuran seberapa jauh suatu produk memenuhi persyaratan atau spesifikasi kualitas yang telah ditetapkan". Pengertian mutu secara garis besar adalah gambaran dan karakteristik menyeluruh dari produk atau jasa yang menunjukkan kemampuannya dalam memenuhi kebutuhan, harapan, dan kepuasan pelanggan.
Orientasi terhadap mutu membutuhkan sistem penjaminan mutu agar mutu dapat ditingkatakan secara berkelanjutan. Sistem penjaminan mutu (Quality Assurance System) dalam suatu institusi pendidikan merupakan tuntutan eksternal dan internal. Sesuai Undang-Undang Nomor 20 Tahun 2003 disebutkan bahwa pengelolaan satuan pendidikan tinggi dilaksanakan berdasarkan prinsip otonomi, akuntabilitas, jaminan mutu, dan evaluasi yang transparan. Lebih jauh, dalam Undang-undang Nomor 12 Tahun 2012 pasal 52 dinyatakan bahwa penjaminan mutu pendidikan tinggi merupakan kegiatan sistemik untuk meningkatkan mutu pendidikan tinggi secara berencana dan berkelanjutan. Penjaminan mutu tersebut dilakukan melalui penetapan, pelaksanaan, evaluasi, pengendalian, dan peningkatan standar pendidikan tinggi. Mutu pendidikan di perguruan tinggi yang paling sering didefinisikan sebagai "kesesuaian untuk tujuan", maka jaminan mutu mengacu pada kebijakan, sikap, tindakan dan prosedur yang diperlukan untuk memastikan mutu yang sedang dipertahankan dan ditingkatkan. Jaminan mutu tersebut dimaksudkan untuk menjamin akuntabilitas dan/atau untuk membawa perbaikan.

Hedwig \& Polla (2006, pp.1-3) menjelaskan bahwa penjaminan mutu merupakan pekerjaan rutin yang berkesinambungan dan harus terus menerus dilakukan dan bukan merupakan kegiatan yang bersifat ad hoc. Oleh karenanya, proses pengawasan (monitoring) dan evaluasi perlu diterapkan secara terus menerus dengan penekanan bahwa kegiatan ini bukan mencari-cari kesalahan melainkan untuk melakukan tindakan perbaikan terus menerus. Sistem penjaminan mutu (quality assurance system) akan menghasilkan lulusan perguruan tinggi yang baik, kreatif, inovatif dan mampu menciptakan lapangan kerja dengan ilmu pengetahuan dan teknologi yang dimilikinya yang merupakan indikator keberhasilan dari pendidikan tinggi yang bermutu. Sistem penjaminan mutu pendidikan adalah sistem yang dirancang untuk meningkatkan mutu pendidikan secara terprog- 
ram dan berkelanjutan melalui tahap penetapan, pelaksanaan, evaluasi, pengendalian, dan peningkatan standar pendidikan. Sistem penjaminan mutu (quality assurance system) digunakan untuk menghasilkan lulusan yang mampu mengembangkan ilmu pengetahuan dan teknologi sebagai indikator keberhasilan dari pendidikan yang bermutu.

Total Quality Management adalah sebuah pendekatan untuk meningkatkan daya saing, efektivitas dan fleksibelitas dari keseluruhan organisasi. TQM adalah sistem manajemen yang fokus pada orang yang bertujuan untuk meningkatkan kepuasan pelanggan dengan pengeluaran biaya yang rendah. Macdonald (1993, p.6) menyatakan bahwa "TQM is therefore a change agent which is aimed at providing a customer-driven organisation". TQM adalah agen perubahan yang ditujukan untuk mengarahkan organisasi agar berorientasi pelanggan. Dengan demikian semua aktivitas dalam organisasi ditujukan untuk memenuhi kebutuhan dan kepuasan pelanggan. Total Quality Management tidak bekerja untuk kepentingan orang lain, tetapi fokus pada kepentiangan pelanggan. Pemahaman ini tidak hanya diperuntukkan bagi manajer senior saja, melainkan untuk semua orang yang ada dalam organisasi.

Reynolds (1994, pp.7-8) menyatakan: "TQM aims to meet customer expectations, and were possible exceed them. Moreover these expectations are contantly increasing. Five years ago I was satisfied with a train journey from London to Leeds which lasted three hours. Now I expect it to last only two. TQM recognizes that customer expectations will usually increase over time, and it is therefore a philosophy of continuous improvement. TQM itself is a journey, not a destination". TQM bertujuan untuk memenuhi harapan pelanggan, dan jika memungkinkan bisa melebihinya. Selain harapan pelanggan terus berubah dan meningkat dari waktu ke waktu, dan karenanya TQM merupakan filosofi dari perbaikan terus-menerus (continuous improvement). TQM sendiri bukan menjadi tujuan akhir, tetapi tujuan antara yang masih mengalami proses yang panjang.
Permendiknas Nomor 63 Tahun 2009 Pasal 1 ayat (1) menjelaskan bahwa "mutu pendidikan adalah tingkat kecerdasan kehidupan bangsa yang dapat diraih dari penerapan sistem pendidikan nasional". Sejalan dengan peraturan tersebut, maka penjaminan mutu pendidikan dilaksanakan sebagai upaya untuk memastikan bahwa proses yang dilakukan oleh institusi pendidikan sesuai dengan standar yang ditentukan. Konsep implementasi manajemen mutu terpadu dalam dunia pendidikan adalah institusi pendidikan memposisikan dirinya sebagai institusi jasa atau dengan kata lain menjadi industri jasa. Jasa yang diberikan kepada pelanggan merupakan sesuatu yang bermutu dan memberikan kepuasan pada pelanggan/stakeholders. Untuk itu institusi pendidikan membutuhkan suatu sistem manajemen yang mampu memberdayakan institusi agar lebih bermutu. Keberhasilan penerapan manajemen mutu merpadu di dalam organisasi pendidikan memerlukan komitmen dan kerja sama antar organsisasi pendidikan, baik tingkat pusat dan daerah, serta organisasi pendidikan setempat sebagai pihak yang berhubungan langsung dengan masyarakat. Jika manajemen mutu terpadu ini diterapkan sesuai ketentuan dengan mempertimbangkan dinamika perkembangan dunia pendidikan dan masyarakat, maka akan terjadi perubahan yang cukup efektif bagi peningkatan mutu pendidikan nasional.

Istilah pendidikan tinggi dan perguruan tinggi sering dipersepsikan sama, sedangkan sebenarnya kedua istilah tersebut memiliki arti yang berbeda. Pendidikan tinggi adalah pendidikan pada jalur pendidikan sekolah pada jenjeng yang lebih tinggi daripada pendidikan menengah. Perguruan tinggi adalah satuan pendidikan yang menyelenggarakan pendidikan tinggi. Markum (2007, p.19) menyatakan: "Perguruan tinggi adalah satuan pendidikan yang menyelenggarakan pendidikan tinggi, yaitu pendidikan di atas jenjang pendidikan menengah, yang mencakup program pendidikan diploma, sarjana, magister, spesialis, dan doktor. Pendidikan 
tinggi diselenggarakan untuk menyiapkan peserta didik untuk menjadi anggota masyarakat yang memiliki kemampuan akademik dan/atau profesional yang dapat menerapkan, mengembangkan dan/atau menciptakan ilmu pengetahuan, teknologi dan/atau kesenian".

Mishra (2007, p.5) menyatakan: "In term of level, higher education includes college and university teaching-learning towards which students' progress to attain higher educational qualification. Higher education imparts in-depth knowledge and understanding so as to advance the student to new frontiers of knowledge in different walks of life (subject dominans). It is about knowing more and more about less and less. It develops the student's ability to question and seek truth and makes him/her competent to critique on contemporary issues. It broadens the intellectual powers of the individual within in a narrow specialization, but also give him/her a wider perspective of the world arround". Pendidikan tinggi yang termasuk di dalamnya adalah kegiatan pembelajaran di perguruan tinggi dan universitas mengarahkan mahasiswa untuk mencapai kualifikasi pendidikan yang lebih tinggi. Pendidikan tinggi menanamkan pengetahuan dan pemahaman yang mendalam sehingga mahasiswa dapat menjadi pembaharu dalam kehidupan masyarakat. Tampubolon (2001, p.71) mengatakan bahwa pendidikan tinggi dipahami sebagai proses produksi dan penyajian jasa pendidikan bertaraf akademik dan profesional, atau jasa pendidikan tinggi, yang dapat dilaksanakan bagi para calon mahasiswa yang sudah memperoleh jasa pendidikan dasar dan menengah. Dan PT adalah lembaga pendidikan yang memproduksi dan menyajikan jasa kependidikan tinggi. Pendidikan tinggi diselenggarakan untuk menyiapkan peserta didik menjadi manusi yang memiliki kemampuan akademik dan profesional untuk mencerdaskan kehidupan bangsa.

Perguruan tinggi memiliki ciri khas yang membutuhkan model pengelolaan yang berbeda dari model pengelolaan pemerintahan, bisnis maupun industri. Model pengelolaan perguruan tinggi lebih bergantung pada inisiatif dan kreativitas individu, serta merupakan sistem kolegial yang berjalan seiring dengan kebebasan akademik dan otonomi keilmuan. Model pengelolaan perguruan tinggi harus mampu untuk mewujudkan visi dan misinya, serta mampu menjawab kebutuhan stakeholders. Sejalan dengan prinsip otonomi dan akuntabilitas dalam pengelolaan perguruan tinggi, di dalam HELTS 2003-2010 dengan jelas menyebutkan bahwa untuk menjadi suatu organisasi yang sehat dan mampu menyelenggarakan pendidikan tinggi yang bermutu, efisien, produktif, dan akuntabel terhadap stakeholders-nya, serta mampu beradaptasi terhadap perubahan peran dan fungsi Ditjen Dikti, maka perguruan tinggi perlu dikelola secara otonomi.

Akuntabilitas dalam pendidikan tinggi memberikan nilai lebih pada ilmu pengetahuan tertentu, pengajaran, hasil pendidikan dan proses manajemen. Tellefsen (1990, p.1) menyatakan: "All colleges and universities are complex organization managed by a board of trustees, a president, and other administrators. Institutions of higher education also share an organizational structure that ancompasses a number of academic and non academic department grouped into four generals areas: academic affairs, student affairs, advancement or development, and business and finacial affairs. Each of these areas contributes to the institution's societal purposes of accumulating, storing, and disseminating knowledge". Perguruan tinggi dan universitas merupakan organisasi yang kompleks yang dikelola oleh dewan pengawas, ketua, dan tenaga administrasi lainnya. Lembaga pendidikan tinggi dilengkapi dengan struktur organisasi yang terdiri dari bagian akademik dan non-akademik, yang dikelompokkan menjadi empat bidang/urusan yaitu: urusan akademik, urusan kemahasiswaan, urusan perencanaan dan pengembangan, dan urusan bisnis dan keuangan. Masingmasing bidang/urusan memberikan kontribusi untuk tujuan sosial lembaga dalam menghimpun, menyimpan, dan menyebarluaskan pengetahuan. 
Wijatno (2009, p.17) menyatakan: "Sebagai satuan pendidikan, PT merupakan wilayah otonom dan mandiri yang berhak mengelola sendiri lembaganya sebagai pusat penyelenggaraan pendidikan tinggi, penelitian ilmiah, dan pengabdian kepada masyarakat. Adapun maksud dan tujuan pemberian otonomi tersebut diberikan dalam rangka pengembangan ilmu pengetahuan dan teknologi, pengembangan diri pada civitas academica, serta berpedoman pada norma dan kaidah keilmuan itu sendiri". Pengelolaan perguruan tinggi sebagai satuan pendidikan yang menyelenggarakan pendidikan tinggi secara otonom harus dilakukan dengan memperhatikan prinsip akuntabilitas, transparansi, nirlaba, penjaminan mutu, dan efektivitas-efisiensi. Fungsi dan peran perguruan tinggi sangat vital, yaitu sebagai: (a) wadah pembelajaran mahasiswa dan masyarakat; (b) wadah pendidikan calon pemimpin bangsa; (c) pusat pengembangan ilmu pengetahuan dan teknologi; (d) pusat kajian kebajikan dan kekuatan moral untuk mencari dan menemukan kebenaran; dan (e) pusat pengembangan peradaban bangsa.

Pertumbuhan dan perkembangan perguruan tinggi di Indonesia dewasa ini mengalami persaingan yang semakin ketat. Hal ini disebabkan antara lain oleh dampak globalisasi, kemajuan dalam bidang ilmu pengetahuan dan teknologi serta jumlah perguruan tinggi yang semakin banyak. Disisi lain, animo para lulusan sekolah menengah atas untuk melanjutkan pendidikan ke jenjang lebih tinggi di perguruan tinggi semakin berkurang yang disebabkan oleh pertimbangan ekonomis dan praktis. UNESCO (2005, p.15) menyatakan: "Commitment to quality by all higher education institutions/providers is essential. To this end, the active and constructive contributions of academic staff are indispensable. Higher education institutions are responsible for the quality as well as the social, cultural and linguistic relevance of education and the standards of qualifications provided in their name, no matter where or how it is delivered". Komitmen terhadap kualitas oleh semua lem- baga/penyelenggara pendidikan tinggi merupakan hal yang sangat mendasar. Untuk itu, kontribusi aktif dan konstruktif staf akademik sangat diperlukan. Lembaga pendidikan tinggi bertanggung jawab atas kualitas serta relevansi sosial, budaya dan bahasa dari pendidikan dan standar kualifikasi yang akan dicapai, dengan berbagai cara yang bisa dilakukan.

Ciri dari sistem penjaminan mutu adalah mengembangkan dan mengadopsi standar dan tingkat kinerja minimum terhadap mutu yang dapat dinilai. Ada dua aspek yang saling terkait standar, yaitu dampak layanan pendidikan tinggi terhadap komunitas lokal, dan standar kualitas teknis program yang ditawarkan. Worthen \& Berry (2002, pp.1-2) menyatakan bahwa definisi kualitas dalam pendidikan tinggi mencakup perhitungan tingkat kelulusan dan total mahasiswa, tingkat penyerapan alumni dalam pekerjaan dan tingkat upah, tingkat penempatan mahasiswa dalam pendidikan lanjut, skor dan standar tes, penggunaan sumber daya yang efisien, pelaporan dan pertanggungjawaban tertulis tepat waktu, aksesibilitas pendidikan untuk semua orang, ukuran kelas dan rasio dosen per mahasiswa, evaluasi berdasarkan pengajaran, pengembangan kemampuan mahasiswa untuk menerapkan praktek pembelajaran baru, dorongan dan fasilitasi dalam pembelajaran sepanjang hayat, kesempatan pengembangan profesional untuk dosen, kegunaan pembelajaran untuk mahasiswa, pengembangan keterampilan dan kebiasaan aktif sebagai warganegara, pengembangan kesadaran kritis, penciptaan kebersamaan, lingkungan pembelajaran yang saling menghormati dan timbal balik di kalangan mahasiswa dan dosen, dan jaminan kebebasan akademik untuk diskusi bagi mahasiswa dan dosen

Dalam pelaksanaan sistem penjaminan mutu pendidikan, perguruan tinggi diharapkan mampu membudayakan internal quality assurance dan external quality assurance. Setelah proses pemahaman tersebut berhasil, maka pada tahap berikutnya adalah merancang dan melaksanakan manajemen penjaminan mutu (quality 
assurance management). Tujuan sistem penjaminan mutu perndidikan tinggi adalah untuk memelihara dan meningkatkan mutu pendidikan tinggi secara berkelanjutan. Perguruan tinggi harus mampu merencanakan, menjalankan, dan mengendalikan suatu proses yang menjamin pencapaian mutu.

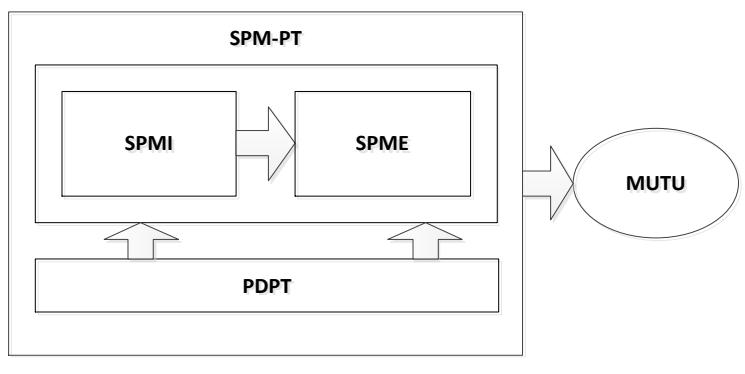

Gambar 1. Sistem Penjaminan Mutu Pendidikan Tinggi Internal dan Eksternal

Perbedaan mendasar antara penjaminan mutu internal dan eksternal adalah bahwa penjaminan mutu internal mengacu pada kebijakan dan praktek dimana lembaga akademik mengevaluasi diri dalam rangka meningkatkan kualitas pendidikan. Penjaminan mutu eksternal mengacu pada kebijakan yang lebih atas untuk menjamin kualitas program dan lembaga pendidikan. Tiga pendekatan untuk menilai kualitas pendidikan di lembaga-lembaga akademik, yaitu dua pendekatan pertama fokus pada kontrol eksternal, termasuk proses yang berasal dari model industri, sedangkan pendekatan ketiga berupa penilaian internal, dengan memberdayakan lembaga dan perubahan dalam budaya organisasi. Ketiga pendekatan tersebut: (1) akreditasi profesional yang didasarkan pada penetapan kriteria untuk menentukan prasyarat kualitas akademik untuk mengalokasikan anggaran dan akreditasi akademik; (2) Pemantauan kualitas eksternal bergantung pada sebuah komite ahli dari luar institusi yang menggunakan proses evaluasi untuk menilai kualitas program; dan (3) audit akademik didasarkan pada kombinasi dari proses evaluasi internal dan laporan kepada pemangku kepentingan. Audit akademik menilai kualitas proses pendidikan dan menentukan apakah sebuah unit melaksanakan kegiatan yang diperlukan untuk memproduksi dan menjamin peningkatan kualitas .

Implementasi sistem penjaminan mutu perguruan tinggi harus didukung oleh ketersediaan data dan informasi tentang perguruan tinggi secara akurat, lengkap, dan mutakhir. Data dan informasi tersebut dikelola oleh suatu pangkalan data pada masing-masing perguruan tinggi. Hasil pelaksanaan penjaminan mutu internal oleh masing-masing perguruan tinggi merupakan bahan dalam pelaksanaan penjaminan mutu eksternal atau akreditasi oleh BAN-PT dan/atau lembaga mandiri lainnya yang diakui pemerintah.

Sistem Penjaminan Mutu Internal (SPMI) adalah kegiatan sistemik penjaminan mutu pendidikan tinggi di perguruan tinggi oleh perguruan tinggi (internally driven), untuk mengawasi penyelenggaraan pendidikan tinggi oleh perguruan tinggi secara berkelanjutan (continuous improvement). SPMI merupakan kegiatan mandiri dari perguruan tinggi yang bersangkutan, sehingga proses tersebut dirancang, dijalankan, dan dikendalikan sendiri oleh perguruan tinggi yang bersangkutan tanpa campur tangan dari pemerintah. SPMI dijalankan oleh perguruan tinggi secara internal untuk mewujudkan visi dan misinya, serta untuk memenuhi kebutuhan stakeholders melalui penyelenggaraan Tridharma Perguruan Tinggi. Konsep SPMI, seperti dikemukakan dalam Kemendiknas (2010, p.17), suatu perguruan tinggi dinyatakan bermutu apabila: perguruan tinggi mampu menetapkan dan mewujudkan visinya; perguruan tinggi mampu menjabarkan visinya ke dalam sejumlah standar dan standar turunan; perguruan tinggi mampu menerapkan, mengendalikan; mengembangkan sejumlah standar dan standar turunan dalam butir untuk memenuhi kebutuhan stakeholders.

Implementasi SPMI di perguruan tinggi dapat dikendalikan melalui berbagai model manajemen kendali mutu. Terdapat beberapa model manajemen yang dapat dipilih, misalnya Model PDCA (Plan, Do, 
Check, Action), Balanced Score Cards, dan Six Sigma. Salah satu model manajemen kendali mutu yang dapat digunakan adalah model PDCA (Plan, Do, Check, Action).

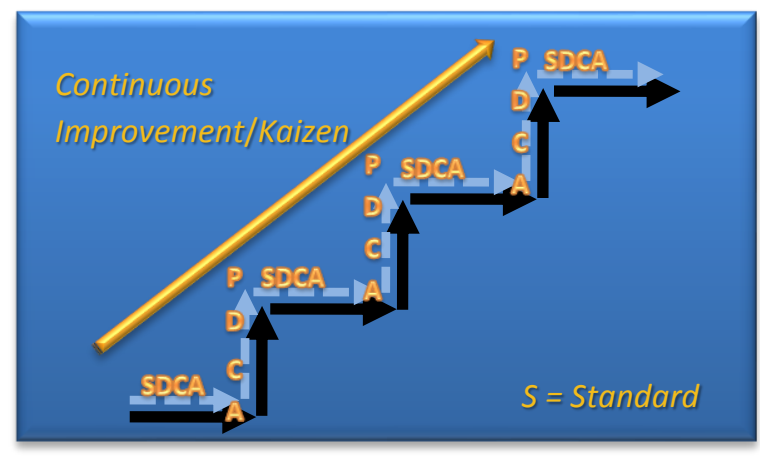

Gambar 2. Manajemen Kendali Mutu berbasis PDCA

Sesuai dengan model manajemen kendali mutu PDCA, maka perencanaan (plan) difokuskan pada perencanaan mutu meliputi penetapan kebijakan mutu, penetapan tujuan mutu beserta indikator pencapaiannya, serta penetapan prosedur untuk pencapaian tujuan mutu. Pelaksanaan (Do) dilakukan terhadap apa yang sudah direncanakan, maka untuk menjamin mutu pendidikan, seluruh proses pendidikan termasuk pelayanan administrasi pendidikan dilaksanakan sesuai dengan SOP. Pada tahap monitoring (Check), pemeriksaan, pengukuran dan evaluasi terhadap pelaksanaan dan hasil pelasanaan termasuk audit mutu internal. Pada tahap tindak lanjut (Action), dilakukan perbaikan dari hasil evaluasi, dengan menyusun rencana perbaikan dan menyusun laporan pelaksanaan program pendidikan.

Pedoman Penjaminan Mutu (Quality Assurance) Pendidikan Tinggi (2003, p.p.1618) lebih lanjut menyebutkan bahwa implementasi SPMI di perguruan tinggi memerlukan syarat agar dapat mencapai tujuannya, yaitu: Komitmen, Sikap Mental, Pengorganisasian. Penyamaan visi dan persepsi kepada sivitas akademika terutama dosen dan tenaga kependidikan untuk selalu merencanakan semua pekerjaan untuk mendukung pencapaian tujuan. Perencanaan terhadap pekerjaan ini sangat penting sebagai kerangka kerja untuk mengukur keberhasilan kerja, sehingga peningkatan mutu secara berkelanjutan dapat terwujud. Pada sisi yang lain, keberhasilan implementasi SPMI juga perlu didukung dengan organisasi SPMI yang kuat dengan independensi yang dimiliki untuk melakukan penjaminan mutu pendidikan melalui kegiatan penjaminan mutu internal. Organisasi SPMI diharapkan mampu menumbuhkan sikap suportif dari seluruh komponen di perguruan tinggi itu terhadap upaya penjaminan mutu pendidikan.

Sistem Penjaminan Mutu Eksternal (SPME) adalah kegiatan sistemik penilaian kelayakan program dan/atau perguruan tinggi oleh Badan Akreditasi Nasional Perguruan Tinggi (BAN-PT) atau lembaga mandiri di luar perguruan tinggi yang diakui pemerintah, untuk mengawasi penyelenggaraan pendidikan tinggi untuk dan atas nama masyarakat sebagai bentuk akuntabilitas publik. Keberadaan BAN-PT diatur dalam Peraturan Pemerintah Nomor 19 Tahun 2005 Pasal 1 butir 27, yang menyatakan: "Badan Akreditasi Nasional Perguruan Tinggi yang selanjutnya disebut BAN-PT adalah badan evaluasi mandiri yang menetapkan kelayakan program dan/atau satuan pendidikan pada jenjang pendidikan tinggi dengan mengacu pada Standar Nasional Pendidikan".

Pemantauan atau penjaminan eksternal mencakup berbagai evaluasi kualitas yang dilakukan oleh individu atau lembaga eksternal untuk lembaga pendidikan tinggi, termasuk akreditasi di tingkat kelembagaan dan program penilaian pengajaran dan kualitas penelitian, audit atau review terhadap prosedur kelembagaan dan pemantauan standar. Esensi dari SPME atau akreditasi adalah penilaian kelayakan dan penjaminan mutu perguruan tinggi atau program studi yang dilakukan oleh organisasi atau badan independen di luar perguruan tinggi (external quality review). Dalam pelaksanaan SPME, mutu perguruan tinggi/program studi merupakan totalitas keadaan dan karakteristik input, proses, dan output atau layanan yang diukur dengan SNP yang menentukan dan mencerminkan mutu perguruan tinggi/ program studi yang bersangkutan. 


\section{Metode Penelitian}

Penelitian ini menggunakan pendekatan kualitatif dengan metode studi kasus. Menurut Yin (2013, p.1), studi kasus merupakan strategi yang lebih cocok digunakan untuk penelitian yang pokok pertanyaannya berkenaan dengan how atau why. Selain itu, studi kasus digunakan bila peneliti hanya memiliki sedikit peluang untuk mengontrol peristiwa-peristiwa yang diselidiki, dan bila fokus penelitian terletak pada fenomena kontemporer (masa kini) di dalam konteks kehidupan nyata. Pada penelitian ini, kasus yang diteliti adalah keberhasilan implementasi Sistem Penjaminan Mutu Internal (SPMI) oleh Universitas Gadjah Mada sebagai upaya meningkatkan mutu pendidikan. Di sisi lain, masih banyak perguruan tinggi yang belum berhasil dalam implementasi SPMI.

Penelitian ini dilaksanakan di Kantor Jaminan Mutu Universitas Gadjah Mada (KJM UGM). Adapun pelaksanaan penelitian mulai bulan Desember 2013 sampai dengan bulan April 2014. Target/Subjek Penelitian ini adalah Kantor Jaminan Mutu (KJM) beserta keseluruhan bagian dan personal yang terlibat dalam kegiatan penjaminan mutu internal UGM, diambil dari pimpinan dan staf KJM UGM yaitu: Kepala dan Wakil Kepala KJM, Sekretaris KJM, dan Koordinator bidang SPMI KJM. Objek penelitian ini adalah Implementasi SPMI oleh KJM UGM yang meliputi: Visi-Misi KJM, Tujuan dan Sasaran KJM UGM, Kebijakan dan konsep sistem penjaminan mutu, Pengorganisasian dan implementasi SPMI, Evaluasi implementasi SPMI, serta Pemanfaatan hasil dan pengembangan SPMI di masa yang akan datang.

Data yang dikumpulkan dalam penelitian ini berupa data kualitatif yang berasal dari hasil pengumpulan data menggunakan teknik pengumpulan data yang sudah disiapkan.

Instrumen pengumpulan data dalam penelitian kualitatif adalah peneliti sendiri. Peneliti adalah sebagai instrumen kunci yang dilengkapi dengan instrumen pendukung lainnya seperti panduan observasi, pedoman wawancara, serta panduan dokumentasi.

Peneliti melakukan pengamatan langsung terhadap berbagai kegiatan pada subjek penelitian, mengamati dan mencatat gedung dan sarana prasarana kantor, sumber daya manusia, serta instrumen dan peralatan teknologi informasi dan komunikasi yang dimanfaatkan dalam implementasi serta evaluasi kegiatan SPMI di KJM UGM.

Dokumentasi dalam penelitian ini dengan mengumpulkan dokumen seperti: surat-surat terkait kegiatan SPMI, pengumuman resmi tentang SPMI, laporan kegiatan SPMI, artikel-artikel dalam bentuk newsletter KJM UGM, informasi kegiatan SPMI yang ada dalam website, dokumen kegiatan, dokumen layanan, dokumen keorganisasian, bagan struktur organisasi, dokumen anggaran yang digunakan dalam implementasi SPMI oleh KJM UGM.

Wawancara dilakukan dengan Ketua KJM, Wakil Ketua KJM, Sekretaris KJM, dan Koordinator Bidang SPMI KJM untuk mendapatkan informasi yang berkaitan dengan implementasi SPMI mulai dari penyusunan standar, pelaksanaan, monitoring, audit mutu internal, rumusan koreksi, sampai tercapainya peningkatan mutu berkelanjutan (continuous quality improvement).

Kriteria yang dapat digunakan untuk meningkatkan dan menentukan keabsahan data, yaitu derajat kepercayaan (credibility), keteralihan (transferability),ketergantungan (dependability) dan kepastian (confirmability). Pada penelitian ini peneliti menggunakan derajat kepercayaan dengan teknik triangulasi, baik pada metode pengumpulan data maupun sumber data. Triangulasi dalam penelitian ini dilakukan melalui pemeriksaan data terhadap metode pengumpulan data, yaitu data hasil observasi berupa catatan lapangan, data hasil dokumentasi berupa surat-surat dan dokument tertulis lainnya, serta data hasil wawancara berupa transkrip wawancara. Trianggulasi juga dilakukan dengan pengecekan data kepada sumber informasi dalam wawancara, membandingkan hasil wawancara dari Ketua dan Wakil Ketua KJM UGM, Sekretaris KJM UGM, dan Kepala Bidang SPMI KJM 
UGM. Selain itu, untuk menjamin keabsahan data wawancara dilakukan konfirmasi antara hasil wawancara dengan informan untuk memastikan kebenaran hasil wawancara (confirmability). Caranya adalah dengan memberikan transkrip hasil wawancara kepada informan untuk diberikan catatan, tambahan informasi, dan diberikan pengesahan/paraf.

Analisis induktif dilakukan dengan tujuan agar data yang diperoleh akan lebih bermakna. Dalam penelitian ini digunakan analisis induktif untuk menarik suatu kesimpulan terhadap hal-hal atau peristiwaperistiwa dari data yang telah dikumpulkan melalui observasi, wawancara, dan dokumentasi, yang bisa ditarik ke arah kesimpulan umum. Analisis data yang digunakan dalam penelitian ini adalan analisis model interaktif dengan kegiatan utama yang saling berkaitan dan terjadi secara bersamaan, yaitu: reduksi data, penyajian data dan penarikan kesimpulan atau verifikasi. Reduksi data merupakan proses pemilihan, penyederhaaan, pemusatan perhatian pada data yang relevan sesuai fokus penelitian. Hal ini dimaksudkan untuk menajamkan, menggolongkan, mengarahkan, membuang yang tidak perlu dan mengorganisir data sedemikian rupa sehingga kesimpulan finalnya dapat ditarik dan diverifikasi. Penyajian Data dengan mengorganisasikan data yang sudah direduksi. Data tersebut disajikan terpisah antara satu tahap dengan tahapan yang lain. Keseluruhan data dirangkum dan disajikan secara terpadu. Dengan melihat penyajian data, maka dapat dipahami apa yang sedang terjadi dan apa yang harus dilakukan. Penarikan kesimpulan/verifikasi dilakukan selama dan sesudah penelitian. Penarikan kesimpulan tersebut berdasarkan pada fenomena dan pola-pola hubungan antar fenomena. Jika belum ditemukan atau belum jelas hubugan yang terjadi antar fenomena, peneliti akan kembali ke lapangan untuk melakukan klarifikasi melalui verifikasi data. Data tersebut kemudian disajikan untuk ditarik kesimpulan sementara, kemudian disempurnakan menjadi kesimpulan akhir.

\section{Hasil Penelitian dan Pembahasan}

Penjaminan mutu pendidikan di perguruan tinggi adalah proses penetapan dan pemenuhan standar mutu pengelolaan pendidikan tinggi secara konsisten dan berkelanjutan, sehingga stakeholders (mahasiswa, dosen, tenaga kependidikan, orang tua, pemerintah, dunia kerja, serta pihak lain yang berkepentingan) memperoleh kepuasan. KJM UGM telah menyusun konsep dan kebijakan sistem penjaminan mutu internal UGM. Konsep dan kebijakan SPMI tersebut meliputi definisi penjaminan mu$\mathrm{tu}$, siklus implementasi penjaminan mutu, organisasi, sistem dokumentasi, dan sumber daya manusia.

UGM mendirikan organisasi penjaminan mutu yang diberi nama Kantor Jaminan Mutu (KJM) pada tanggal 27 November 2001 sesuai dengan SK Rektor Nomor 123/P/SK/Set.R/2001. Sesuai dengan Struktur Organisasi dan Tata Kerja (SOTK), KJM UGM berada langsung di bawah rektor. Tugas KJM UGM adalah merencanaan dan melaksanaan sistem jaminan mutu secara keseluruhan di Universitas Gadjah Mada, dan melaporkan secara berkala pelaksanaan sistem jaminan mutu di UGM kepada rektor. KJM UGM dibantu oleh organisasi penjaminan mutu tingkat fakultas yaitu Gugus Jaminan Mutu (GJM) dan Komisi Koordinasi Kegiatan Akademik (K3A). Sebagai partner kerja penjaminan mutu di tingkat jurusan dan program studi, maka dibentuk Tim Koordinasi Kegiatan Akademik (TK2A), dan Tim Koordinasi Semester (TKS).

Sistem Penjaminan Mutu Internal (SPMI) adalah kegiatan sistemik penjaminan mutu pendidikan oleh perguruan tinggi untuk mengawasi penyelenggaraan pendidikan tinggi oleh perguruan tinggi itu sendiri secara berkelanjutan untuk kepuasan stakeholders. Implementasi SPMI di UGM dilaksanakan sebagai sebuah keharusan karena mutu pendidikan tidak hanya tergantung pada pemerintah tetapi juga tergantung pada penilaian para pemangku kepentingan. Implementasi SPMI di UGM merupakan kegiatan mandiri, sehingga 
proses penjaminan mutu dirancang, dilaksanakan, dikendalikan, dan dievaluasi sendiri tanpa campur tangan pemerintah. Hal ini sesuai dengan Ditjen Dikti Kemendiknas (2010, p.15) yang menyatakan bahwa SPMI di perguruan tinggi dilakukan sepenuhnya oleh perguruan tinggi sendiri, tanpa campur tangan pemerintah.

Implementasi SPMI sebagai bagian integral dari sistem penjaminan mutu pendidikan UGM dilaksanakan dengan penyusunan rancangan SPMI yang secara operasional disebut Siklus SPMI UGM yang dilaksanakan mengikuti periode satu tahunan. Siklus SPMI UGM terdiri atas tujuh langkah atau tahap, yaitu: (a) penetapan Standar, (b) pelaksanaan, (c) monitoring, (d) evaluasi diri, (e) audit mutu internal, (f) rumusan koreksi, dan (g) peningkatan mutu.

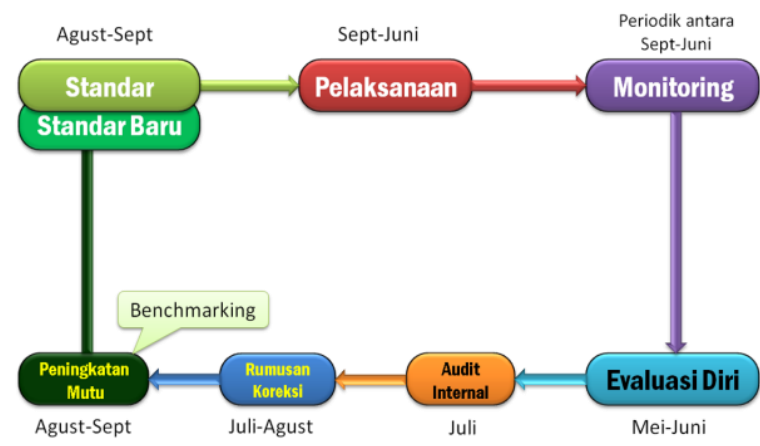

Gambar 3. Siklus Sistem Penjaminan Mutu Internal di UGM

Penetapan standar-standar dirumuskan berdasarkan peraturan perundang-undangan, hasil evaluasi diri tentang kinerja yang sedang berjalan, masukan dari stakeholders, hasil studi pelacakan (tracer study), dan kebijakan pengembangan penjaminan mutu Ditjen Dikti. Standar yang ditetapkan dalam SPMI UGM mengacu pada Standar Nasional Pendidikan (SNP). Tahapan dalam pelaksanaan SPMI di UGM adalah: sosialisasi SPMI; bantuan teknis program studi; sosialisasi audit mutu internal (AMI) dan instrumen evaluasi diri program studi (EDPS), pengisian EDPS; pelaksanaan AMI; tindakan koreksi/tindakan perbaikan; rapat tinjauan manajemen tingkat fakultas untuk membahas tentang temuan audit dan peningkatan mutu program studi; rapat tinjauan manajemen tingkat univer- sitas, untuk membahas temuan yang diperoleh di program studi yang tidak dapat diselesaikan di tingkat program studi; jurusan, dan fakultas akan dibawa ke tingkat universitas.

Monitoring bertujuan untuk mengawal implementasi SPMI yang di-laksanakan berdasarkan rencana. Evaluasi Diri merupakan upaya sistematik untuk menghimpun dan mengolah data (fakta dan informasi) yang handal dan sahih sehingga dapat disimpulkan kenyataan yang dapat digunakan sebagai landasan tindakan manajemen untuk mengelola kelangsungan lembaga, seperti fakultas, jurusan, dan program studi. AMI adalah audit penjaminan dan konsultasi yang independen serta objektif terhadap kegiatan operasional akademik atau proses akademik. Rumusan koreksi didasarkan pada temuan audit mutu intermal yang ditindaklanjuti dengan rapat tinjauan manajemen di tingkat prodi, fakultas, dan universitas. Rumusan koreksi selanjutnya akan menjadi bahan untuk mengkaji ulang (review) audit mutu internal berikutnya, apakah sudah ada tindakan perbaikan yang dilakukan. Hasil rumusan koreksi mengarahkan pada peningkatan mutu melalui penetapan standar/perencanaan baru pada tahapan selanjutnya. Peningkatan mutu yang sesungguhnya pada akhirnya akan ditentukan oleh masyarakat sebagai stakeholders eksternal. Peningkatan mutu sebagai dampak implementasi SPMI di UGM secara menyeluruh.

Implementasi SPMI di UGM didukung oleh sumber daya manusia (SDM) yang memiliki kompetensi dalam bidang penjaminan mutu. KJM UGM saat ini memiliki 365 orang tenaga auditor AMI yang aktif dari 402 orang yang terdaftar sebagai tenaga auditor. Selain itu, KJM UGM juga memiliki 74 orang auditor internal ISO 9001, 65 orang asesor BAN PT, 6 orang yang telah lulus sebagai asesor Malcolm, dan 3 orang sebagai asesor ASEAN University Network Quality Assurance (AUNQA). Implementasi SPMI di UGM juga ditunjang dengan pembiayaan yang memadai melalui anggaran yang sudah ditetapkan 
dalam Rencana Kegiatan dan Anggaran Tahunan (RKAT) serta Biaya Operasio-nal Perguruan Tinggi Negeri (BOPTN). Anggaran untuk pembiayaan implemen-tasi SPMI cukup besar, meliputi RKAT dari KJM UGM sendiri ditambah dengan RKAT dari fakultas, jurusan dan program studi yang ada. Menurut dokumen KJM UGM, total anggaran yang digunakan dalam implementasi SPMI tahun 2013 mencapai Rp1.568.205.966,00. Anggaran tersebut belum termasuk anggaran dari masing-masing fakultas, jurusan, dan program studi yang juga memasukkan anggaran penjaminan mutu dalam RKAT masing-masing.

Kinerja KJM UGM didukung sarana dan prasarana yang memadai dengan menempati bangunan Kantor Pusat Tata Usaha UGM, lantai 2 sayap selatan dengan luas ruangan kurang lebih $170 \mathrm{~m} 2$, yang terbagi menjadi 3 bagian yaitu ruang pimpinan, ruang rapat, dan ruang administrasi. KJM UGM memiliki 5 unit komputer, 4 LCD projector, 1 unit mesin fotokopi, 9 unit printer, 7 unit pesawat telepon, 5 saluran telepon, 3 unit white screen, 1 unit scanner, dan 1 unit microphone. Selain itu sarana kerja seperti meja, kursi, almari, dan alat tulis kantor dan lain sebagainya juga tersedia. Perangkat komputer dan perlengkapannya, jaringan internet untuk teknologi informasi dan back up ketersediaan data. Sarana dan prasarana non fisik yang digunakan seperti software teknokogi informasi dan komunikasi serta sistem dokumentasi kegiatan dosen dan sivitas akademika lainnya yang dikembangkan melalui model virtual dengan menggunakan data base dalam website.

Kendala Implementasi SPMI karen kurangnya komitmen pimpinan dihadapi dengan cara menyediakan tenaga yang memang expert di bidang penjaminan mutu. Pimpinan yang memiliki multi tugas, baik sebagai pendidik sekaligus sebagai personal penjaminan mutu, dirasakan kurang optimal hasil kerjanya. Kendala kurangnya jumlah tenaga auditor yang dimiliki KJM ditempuh dengan cara memprogramkan pelatihan auditor baru. Program pelatihan auditor baru dan refreshing auditor lama di- laksanakan intensif setiap tahun. Kendala Implementasi SPMI sering terjebak menjadi kegiatan rutinitas dihadapi dengan merefresh dan membangun semangat baik di tataran pimipinan universitas, fakultas, jurusan, dan program studi serta para auditor sendiri. KJM UGM juga menciptapkan program-program yang sifatnya menyadarkan posisi penting penjaminan mutu seperti secara berkala bertemu dalam forum kegiatan penyegaran dan peningkatan mutu auditor. Selain itu, interaksi dengan para penggiat penjaminan mutu internal perguruan tinggi dalam forum SPMI Dikti, BAN PT, ASEAN University Network (AUN), dan Dialogue on Innovative Higher Education Strategies (DIES) juga selalu menambah percaya diri dan semangat untuk bersikap dewasa dan bertindak dengan landasan sebagai agen perubahan secara internal dan eksternal, baik dalam skala nasional maupun internasional. Program tersebut dirancang untuk meningkatakan kesadaran dalam rangka membangun budaya mutu.

Implementasi SPMI memerlukan sistem evaluasi untuk menilai efektivitas dari pelaksanaan penjaminan mutu internal tersebut. KJM UGM setiap tahun mengadakan evaluasi, dengan meminta masukan dari para auditor, dari pimpinan fakultas dan prodi yang diaudit, dan pimpinan universitas. Evaluasi dilakukan dalam bentuk workshop, yang membahas masukan dan koreksi terhadap pelaksanaan Audit Mutu Internal. Evaluasi implementasi SPMI selain membahas efektivitas pelaksanaan SPMI juga mengevaluasi bagaimana faktor pendukung dapat memberikan kontribusi yang optimal, seperti faktor pembiayaan, SDM, dan sarana dan prasarana pendukung.

Implementasi SPMI secara internal dimanfaatkan untuk peningkatan mutu pendidikan dalam tahap perencanaan. Temuan-temuan dalam SPMI akan dijadikan masukan untuk memperbaiki standar dan meningkatkan menjadi lebih baik lagi. Pemanfaatan hasil implementasi SPMI selain digunakan dalam perencanaan pendidikan, juga digunakan untuk menumbuhkan semangat bekerja lebih baik, membangkitkan 
kesadaran untuk membangun budaya mu$\mathrm{tu}$, sehingga akan terwujud perbaikan yang terus menerus (continuous quality inprovement). Secara eksternal, hasil implementasi SPMI dimanfaatkan terkait dengan persiapan dalam menghadapi akreditasi pihak eksternal, dalam hal ini adalah Badan Akreditasi Nasional (BAN PT). KJM-UGM juga telah membantu universitas dalam penyusunan portofolio akreditasi institusi Badan Akreditasi Nasional Perguruan Tinggi (BAN PT). Pemanfaatan hasil implementasi SPMI di UGM juga dimanfaatkan untuk persiapan akreditasi dan sertifikasi tingkat internasional yang dilakukan pada beberapa unit. KJM UGM sendiri telah memperoleh ISO 9001 9001:2000 dari Worldwide Quality Assurance (WQA) tahun 2008, dan International Organization for Standardization (ISO) 9001:2008 dari SGS tahun 2011.

Implementasi SPMI di UGM didasarkan pada dua dokumen, yaitu Dokumen Akademik dan Dokumen Mutu. Dokumen Akademik yang berada pada tingkat universitas dan fakultas terdiri atas dokumen Kebijakan Akademik, Standar Akademik, dan Peraturan Akademik. Dokumen Akademik di tingkat program studi terdiri atas Spesifikasi Program Studi, Kurikulum, Peta Kurikulum, dan Rencana Program dan Kegiatan Pembelajaran Semester (RPKPS). Dokumen Mutu yang dikembangkan di UGM mengacu pada Sistem Manajemen Mutu ISO 9001:2008. Dokumen Mutu terdiri atas Manual Mutu pada tingkat universitas atau fakultas, Prosedur Mutu, dan Instruksi Kerja. Prosedur Mutu dan Instruksi Kerja disusun dan diimplementasikan pada masing-masing unit kerja. Dalam penjaminan mutu penelitian dan pengabdian kepada masyarakat, KJM UGM melakukan pendampingan untuk memastikan bahwa semakin banyak jurnal di UGM yang terakreditasi. Penjaminan mutu penelitian juga terkait dengan mutu laboratorium, dengan sertifikasi dan akreditasi laboratorium yang dimiliki UGM. Rancangan SPMI yang secara operasional disebut Siklus SPMI UGM dikembangkan sejalan dengan model manajemen kendali mutu model Kaizen dengan mengoperasikan
PDCA (Plan, Do, Check, Action) dan SDCA (Standard, Do, Check, Action) yang memungkinkan tercapainya Kaizen atau Ginong Pratidino atau perbaikan secara terus.

\section{Simpulan dan Saran}

\section{Simpulan}

Konsep dan kebijakan SPMI di UGM diartikan sebagai suatu proses yang berkelanjutan peningkatan mutu pendidikan melalui kegiatan penetapan standar, pelaksanaan, monitoring, evaluasi diri, audit mutu internal, sampai dengan benchmarking untuk menentukan standar baru, yang disebut sebagai siklus penjaminan mutu. Pengorganisasian SPMI di UGM dilaksanakan oleh organisasi penjaminan mutu yang diberi nama Kantor Jaminan Mutu (KJM UGM) yang bertugas untuk merencanakan dan melaksanakan sistem penjaminan mutu secara menyeluruh. Implementasi SPMI di UGM dilaksanakan dengan penyusunan rancangan SPMI yang secara operasional disebut Siklus SPMI yang dilaksanakan mengikuti periode satu tahunan. Siklus SPMI terdiri atas tujuh langkah atau tahap, yaitu: penetapan standar, pelaksanaan, monitoring, evaluasi diri, audit mutu internal, rumusan koreksi, dan peningkatan mutu untuk kepuasan stakehorders.

Kendala yang dihadapi dalam implementasi SPMI di UGM adalah: komitmen pimpinan relatif kurang, jumlah tenaga auditor yang masih terbatas, kegiatan SPMI sering terjebak menjadi kegiatan rutin. Langkah yang ditempuh menghadapi kendala: menyediakan tenaga yang expert di bidang penjaminan mutu, memprogramkan pelatihan auditor baru dan refreshing auditor lama dilaksanakan intensif, membangun semangat baik pimipinan universitas, fakultas, jurusan, dan program studi. Evaluasi Implementasi SPMI di UGM dilaksanakan setiap tahun, dengan meminta masukan dari para auditor, dari pimpinan fakultas dan prodi yang diaudit, dan pimpinan universitas.

Pemanfaatan hasil implementasi SPMI di UGM secara internal untuk peningkatan mutu pendidikan, menumbuhkan 
semangat bekerja lebih baik, membangkitkan kesadaran untuk membangun budaya mutu. Secara eksternal dimanfaatkan terkait dengan persiapan dalam menghadapi akreditasi nasional maupun internasional. Pengembangan implementasi SPMI di UGM mengacu pada Sistem Manajemen Mutu International Organization for Standardization (ISO), menerapkan standar Badan Akreditasi Nasional Perguruan Tinggi (BAN PT) sebagai standar minimal pengelolaan program studi dan universitas.

Saran

Berdasarkan simpulan dari hasil penelitiaan dapat diberikan saran yaitu perlu dilaksanakan kegiatan training dan refreshing yang dikemas dengan cara yang lebih interaktif seperti outbound, game kekompakan dan kedisiplinan untuk membentuk tim yang solid dalam rangka implementasi SPMI yang efektif dan efisien. Perlu mempercepat usaha mencetak tenaga penuh waktu dari tenaga kependidikan yang di-upgrade pengetahuan dan wawasannya sesuai kompetensi yang dibutuhkan. Hendaknya kegiatan sosialisasi intensif melibatkan peran aktif seluruh sivitas akademika di berbagai kegiatan penjaminan mutu dalam rangka meningkatkan mutu pendidikan di UGM.

\section{Daftar Pustaka}

Ditjen Dikti Depdiknas. (2003). Pedoman penjaminan mutu (quality assurance) pendidikan tinggi. Jakarta: Ditjen Dikti Depdiknas.

Ditjen Dikti Depdiknas. (2004). Strategi jangka panjang pendidikan tinggi (HELTS) 2003-2010 menuju sinergi kebijakan nasional. Jakarta: Ditjen Dikti Depdiknas.

Ditjen Dikti Kemendiknas. (2010). Sistem penjaminan mutu perguruan tinggi (SPM-PT). Jakarta: Ditjen Dikti Kemendiknas.

Hedwig, R. \& Polla, G. (2006). Model sistem penjaminan mutu dan proses penerap- annya di perguruan tinggi. Yogyakarta: Graha Ilmu

Kemendiknas. (2009). Permendiknas Nomor 63, Tahun 2009, tentang sistem penjaminan mutu pendidikan.

Macdonald, J. (2005). Understanding total quality management in a week, London: St Edmundsbury Press.

Markum, M.E. (2007). Pendidikan tinggi dalam perspektif sejarah dan perkembangannya di Indonesioa, Jakarta: Direktorat Jenderal Pendidikan Tinggi Departemen Pendidikan Nasional.

Mishra, S. (2007). Quality assurance in higher education: An introduction, Bangalore, India: National Assessment and Acreditation Council.

Oakland, J.S. (1995). Total quality management: The route to improving performance, London: Butterworth-Heinemann Ltd.

Presiden. (2005). Peraturan Pemerintah RI Nomor 19, Tahun 2005, tentang standar nasional pendidikan.

Republik Indonesia. (2003). Undang-undang RI Nomor 20, Tahun 2003, tentang sistem pendidikan nasional.

Republik Indonesia. (2012). Undang-undang Nomor 12, Tahun 2012, tentang pendidikan tinggi.

Reynolds, L. (1994). Beyond total quality management. Great Britian: Sheldon Press.

Tampubolon, D.P. (2001). Perguruan tinggi bermutu perguruan, paradigma baru manajemen pendidikan inggi menghadapi tantangan abad 21. Jakarta: Gramedia Pustaka Utama.

Tellefsen, T.E. (1990). Improving college management: An integrated system approach. California: Jossey-Bass Inc., Publishers.

Tjiptono, F. \& Diana, A. (1995). Total quality management. Yogyakarta: Andi Offset. 
UNESCO. (2005). Guidelines for quality provision in cross-border higher education. Paris: the United Nations Educational, Scientific and Cultural Organization.

Universitas Gadjah Mada. (2013). Sistem penjaminan mutu internal UGM: Sejarah, implementasi, dan pengembangan. Yogyakarta: Kantor Jaminan Mutu UGM.

Wijatno, S. (2009). Pengelolaan perguruan tinggi secara efisien, efektif, dan ek- onomis untuk meningkatkan mutu penyelenggaraan pendidikan dan mutu lulusan. Jakarta: Salemba Empat.

Worthen, H. \& Berry, J. (2002). Bargaining for "Quality" in Higher Education: A Case Study from the City Colleges of Chicago (Versi elektronik). Labor Studies Journal, 27, 1-23.

Yin, R.K. (2013). Case study reasearch: Design $\mathcal{E}$ methods. California: Sage Publications, Inc. 